\title{
Respiratory heat and moisture loss is associated with eosinophilic inflammation
} in asthma

\author{
D.D. Noble, J.B. McCafferty, A.P. Greening and J.A. Innes
}

ABSTRACT: Increased mucosal vascularity is a hallmark of airway inflammation in asthma. It was hypothesised that this would lead to a detectable increase in respiratory heat and moisture loss (RHML), which would reflect the degree of airway inflammation present.

A total of 23 subjects with asthma and 18 healthy controls had RHML measured in a crosssectional study. The measurements were made using a device that combines temperature and humidity measurement during inspiration and expiration and allows precise control over inspirate conditions and ventilatory pattern. The subjects with asthma underwent parallel measurements of exhaled nitric oxide, sputum eosinophil percentage and exhaled breath condensate $\mathrm{pH}$.

Mean $\pm S D R H M L$ was elevated in patients with asthma $\left(98.1 \pm 7.3 \mathrm{~J} \cdot \mathrm{L}^{-1}\right)$ compared with control subjects $\left(91.9 \pm 4.5 \mathrm{~J} \cdot \mathrm{L}^{-1}\right)$. RHML measurement in asthma correlated with sputum eosinophil percentage.

This novel correlation between thermal and cellular measurements in asthma suggests that both of these noninvasive indices are sensitive to the degree of underlying chronic airway inflammation.

KEYWORDS: Airway inflammation, asthma, exhaled breath condensate $\mathrm{pH}$, exhaled nitric oxide, respiratory heat loss, sputum eosinophils

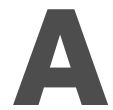

irway inflammation in asthma is characterised by increased mucosal vascularity. This has been demonstrated in bronchial biopsies [1-3] and using high-magnification videobronchoscopy [4]. Airway mucosal blood flow, estimated using a soluble gas uptake method, is also reported to be elevated in patients with asthma compared with control subjects [5]. It was hypothesised that an increase in airway mucosal blood flow associated with airway inflammation in asthmatics would lead to a detectable increase in respiratory heat and moisture loss (RHML).

During normal respiration, a counter-current mechanism for respiratory heat transfer operates [6]. As air is inspired, it is heated and humidified, resulting in cooling and drying of the airway mucosa. By the time air reaches the alveoli it is at body temperature and fully saturated with water vapour. During expiration, a variable fraction of the available heat energy is regained by the mucosa as air exits the lung, and the remainder is exhaled, resulting in net heat loss. Conditioning of inspired air is dependent on a source of heat and water. This comes from airway mucosal blood flow.
There is some evidence to suggest that respiratory heat flux may indeed be altered in asthma, and measurement of respiratory heat loss has been proposed as a marker of lung disease $[7,8]$. PAREDI et al. [9] reported a faster rise in breath temperature during expiration in asthmatics compared with controls. However, in this study measurements were made with subjects breathing ambient room air and evaporative heat loss was not assessed. This is relevant because in resting conditions, the majority of heat exchange takes place in the upper airway and evaporative heat loss is a major component of total heat loss from the respiratory tract [10]. In intubated patients, measurements of tracheal temperature do not accurately predict total respiratory heat losses, but measurement of absolute humidity appears to be a better predictor [11].

The conducting airways become progressively more involved in respiratory heat exchange as either the inspired air temperature is lowered or the minute ventilation is augmented [12]. A potential hazard of these manoeuvres is that they may also alter the airway environment, by changing airway calibre or altering mucosal blood flow. In fact, the main focus of research

\section{AFFILIATIONS}

Respiratory Unit, Western General Hospital, and University of Edinburgh, Edinburgh, UK.

\section{CORRESPONDENCE}

D.D. Noble

Respiratory Unit

Western General Hospital

Edinburgh

UK

Fax: 441315371038

E-mail: donald.noble@

blueyonder.co.uk

Received:

May 282006

Accepted after revision:

November 172006

SUPPORT STATEMENT

D.D. Noble was supported by an unrestricted investigator grant from GlaxoSmithkline (Brentford, UK). J.B. McCafferty was supported by a grant from Chest, Heart and Stroke

Scotland (Edinburgh, UK).

STATEMENT OF INTEREST

None declared.

European Respiratory Journal Print ISSN 0903-1936

Online ISSN 1399-3003 
into respiratory heat exchange in asthma has been the effects of extreme ventilatory conditions on the airway in the pathogenesis of exercise or cold air-induced asthma [13]. To engage the subglottic airway in heat exchange, with the purpose of measuring disease activity, conditions should be used that involve the lower airways in this process without altering their airway structure or function. In contrast to previous studies, the present authors thus used an inspirate of conditioned air with a lower temperature and water content than room air and moderately elevated minute ventilation. These conditions create a modest thermal challenge that does not affect airway calibre, but is still sufficient to engage the lower airway in heat exchange [14].

The aim of the current study was to determine whether RHML measured under these precisely controlled conditions is altered in asthma in association with airway inflammation and whether it bears any relation to the state of inflammation in the airways measured by alternative noninvasive methods. RHML measurements in asthmatic and control subjects were made in a cross-sectional comparison. In the asthmatic group, parallel measurements of exhaled nitric oxide (eNO), sputum eosinophil percentage and exhaled breath condensate (EBC) $\mathrm{pH}$ were made.

\section{METHODS}

\section{Subjects}

A total of 23 subjects with stable persistent asthma and 18 healthy controls were recruited. The subjects in the asthma group were recruited from respiratory outpatient clinics. They had had no exacerbations, nor any oral corticosteroid treatment, for $\geqslant 2$ months prior to the study. Asthma was defined and classified according to Global Initiative for Asthma guidelines [15]. Out of the 23 asthmatic subjects, 11 had severe persistent asthma, eight had moderate persistent asthma and four had mild persistent asthma. Healthy controls were recruited from among hospital staff. All were nonsmokers or ex-smokers (stopped $>6$ months ago) with a smoking history of $<10$ pack-yrs. All asthmatic subjects were taking regular inhaled corticosteroids (mean dose $867 \pm 597 \mu \mathrm{g}$ beclometasone diproprionate or equivalent). In total, 16 of the asthmatic subjects were taking a regular long-acting $\beta_{2}$-agonist (LABA). Inhaled medications were withheld for $12 \mathrm{~h}$ prior to testing. The study was approved by the local ethics committee and all subjects gave written informed consent.

\section{Study design}

RHML and forced expiratory volume in one second (FEV1; Vitalograph, Buckingham, UK) were measured in the asthma and control groups. The asthmatic group underwent parallel measurements of other inflammatory markers after their RHML measurement. To minimise interaction between the measurement techniques, procedures were performed in the following order during a single visit: RHML measurement, eNO measurement, EBC collection, FEV1 and induced sputum collection.

The day-to-day repeatability of RHML measurement was assessed in nine control subjects and eight stable asthmatics, who underwent two measurements on two separate days within a 1-week period.

\section{$\boldsymbol{R H M L}$ apparatus}

RHML was measured using a purpose-built device (fig. 1) incorporating temperature and humidity measurement of inspirate and expirate and allowing precise control over inspiratory conditions and ventilatory pattern. Temperature sensors were K-type thermocouples (chromel-alumel bead type), with a $90 \%$ response time of $50 \mathrm{~ms}$. They were calibrated against a mercury standard prior to testing. Humidity sensors were of thermoset polymer capacitance construction (HIH3602-A; Honeywell, Morristown, NJ, USA), supplied as factory calibrated, giving relative humidity (RH) with an accuracy of $\pm 2 \%$ and an estimated $95 \%$ response time of $5 \mathrm{~s}$. This response time, which is the fastest available from practical sensors, precluded intra-breath measurements, so inspiratory and expiratory flow were separated by a valve and $\mathrm{RH}$ and breath temperature were recorded downstream as time-weighted averages during expiration. It has been calculated that the potential error from using time-weighted values for humidity measurement is an underestimate of $<5 \%$ [16]. Expiratory airflow was measured using an ultrasonic phase-shift flow-meter (FR-413; BRDL, Birmingham, UK), which was calibrated for volume (at ambient temperature and pressure and saturated with water vapour) using standard volume syringes (Vitalograph). The sensor's $100 \%$ response time was $12 \mathrm{~ms}$; linearity was $<2 \%$ and the residual error due to temperature variation $<1 \%$ in the temperature range $0-40^{\circ} \mathrm{C}$.

Target inspiratory air conditions of $10^{\circ} \mathrm{C}$ and $50 \% \mathrm{RH}$ were created using a purpose built air conditioning device. The enthalpy of inspired air was therefore $\sim 20 \mathrm{~J} \cdot \mathrm{L}^{-1}$. An audiovisual feedback system was used to guide subjects to achieve a tidal volume of $1.5 \mathrm{~L}$ (an expiratory flow rate of $500 \mathrm{~mL} \cdot \mathrm{s}^{-1}$ and a respiratory rate of 10 breaths $\cdot \mathrm{min}^{-1}$, to give a target minute ventilation of $15 \mathrm{~L} \cdot \mathrm{min}^{-1}$ ). This degree of elevated ventilation and cool inspirate was selected in order to engage the lower airway in heat exchange. Pilot studies have demonstrated that the thermal challenge of these conditions is not sufficient to affect airway calibre in a 5-min test [14]. Validation studies with this apparatus [16], have shown the calculated moisture

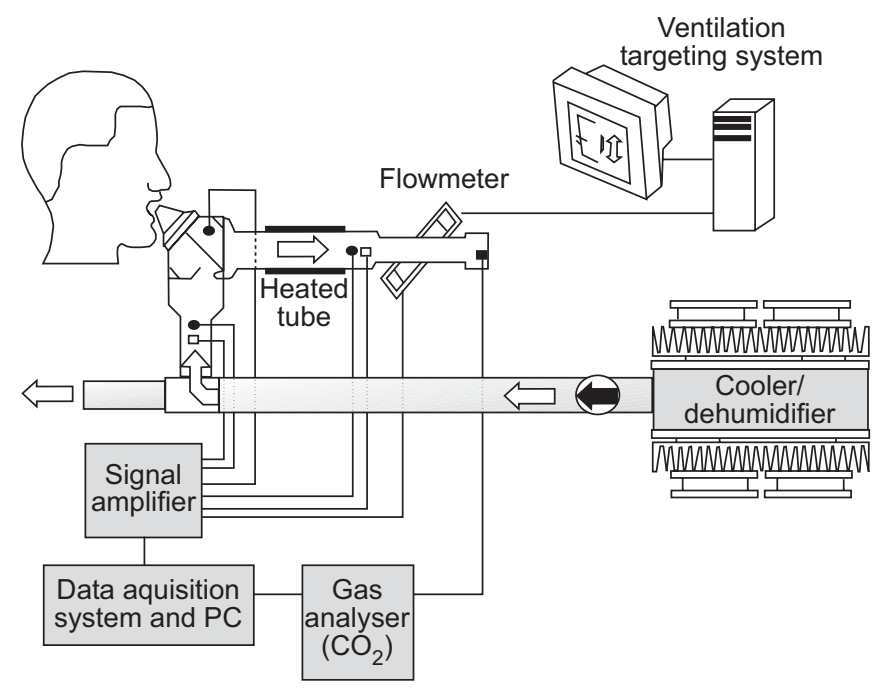

FIGURE 1. Apparatus for measurement of respiratory heat and moisture loss. - : temperature sensor; $\square$ : moisture sensor; $\mathbf{\square}$ : end-tidal $\mathrm{CO}_{2}$ sampling port. 
loss for a range of minute ventilations agrees with published values using the gold standard-freeze out method [10]. Measurements were made after 1-min breathing into the apparatus. It was determined from pilot data that this is the optimum time for detecting alterations in RHML [17], allowing adequate time for the humidity sensors to adjust and the mean exhaled air temperature to reach a steady state.

\section{RHML calculation}

The total heat or energy content of an air/water mixture is given the term enthalpy. Enthalpy values were calculated using a psychrometric calculator (PsyCalc 98; Linric Company, Bedford, NH, USA). The enthalpy of the inspirate and expirate are derived from mean air temperature and $\mathrm{RH}$ during inspiration and expiration respectively. Net enthalpy loss is then calculated as:

$$
\mathrm{h}=\mathrm{he}-\mathrm{hi}
$$

Where $\mathrm{h}=$ net enthalpy loss $\left(\mathrm{J} \cdot \mathrm{g}\right.$ dry $\left.\operatorname{air}^{-1}\right)$, he=enthalpy of expirate and $\mathrm{hi}=$ enthalpy of inspirate.

RHML is then calculated using the following formula:

$$
\mathrm{RHML}=\mathrm{D} \times \mathrm{h}
$$

Where $\mathrm{D}=$ density of air/water vapour mixture $\left(g \cdot \mathrm{L}^{-1}\right)$.

\section{eNO}

Fractional exhaled nitric oxide ( $F$ eNO) was measured in single breath using a target expiratory flow rate of $250 \mathrm{~mL} \cdot \mathrm{s}^{-1}$ $\left(F \mathrm{NO}_{250}\right)$ with a modified chemiluminescence analyser (LR2000; Logan Research Limited, Rochester, UK). The NO analyser was calibrated daily with $\mathrm{N}_{2} / \mathrm{NO}$ calibration gas containing 93 ppb NO (BOC Gases, Guildford, UK). A visual feedback system was used to maintain a mouth pressure of $>5 \mathrm{mmHg}$, sufficient to keep the soft palate closed and prevent nasal contamination. NO measurements were taken from the plateau phase at the end of expiration, in accordance with American Thoracic Society/European Respiratory Society (ERS) guidelines [18]. NO values were recorded as an average of three measurements. The measurement error in repeat measurements in the same individual was $\pm 1.7 \mathrm{ppb}$, giving a $95 \%$ confidence interval (CI) of $\pm 3.3 \mathrm{ppb}$.

\section{EBC $\mathrm{pH}$}

EBC was collected using a purpose-built condenser (EcoScreen; Jaeger, Würzburg, Germany). Subjects, wearing a nose-clip, were asked to breathe through a nonrebreathing two-way valve into the apparatus for $5 \mathrm{~min}$. Exhaled air was conducted through a lamellar condenser to an interchangeable sampling tube (one per sample) situated in a cooling cuff, cooled to $-10^{\circ} \mathrm{C}$. Condensate $\mathrm{pH}$ was measured immediately after collection (nondeaerated) using a calibrated $\mathrm{pH}$-meter incorporating an ion-sensitive field-effect transistor sensor with temperature compensation (KS723; Camlab, Cambridge, $\mathrm{UK})$ with an accuracy of $\pm 0.1 \mathrm{pH}$ units. The $\mathrm{pH}$-meter underwent a two-point calibration prior to each measurement. The day-to-day repeatability of breath condensate $\mathrm{pH}$ in control subjects and patients with bronchiectasis due to cystic fibrosis in the unit has been reported as $\pm 0.08 \mathrm{pH}$ units [19].

\section{Induced sputum processing and analysis}

Sputum was induced using incremental concentrations of 3,4 and $5 \%$ hypertonic saline each delivered over $4 \mathrm{~min}$, via an ultrasonic nebuliser (DeVilbiss Ultraneb 99; DeVilbiss Healthcare, Somerset, PA, USA), set at an output of $\sim 2.4 \mathrm{~mL} \cdot \mathrm{min}^{-1}$. Subjects were pre-treated with $2.5 \mathrm{mg}$ salbutamol via a nebuliser. FEV1 was monitored closely throughout the test and the procedure was abandoned if FEV1 decreased by $>20 \%$. Sputum processing was performed using the methods described by PAVORD et al. [20]. A haematoxylin and eosin stain was used for the cytospins. Sputum differential cell counts were calculated from counting 400 inflammatory cells and expressed as percentages of total inflammatory cell count. When sputum eosinophil cell percentage was counted on two separate occasions in 12 sputum samples from subjects with asthma, the correlation coefficient was $r=0.98(p<0.001)$. The intra-observer $95 \% \mathrm{CI}$ was $\pm 2.46 \%$.

FEV1 was measured to ERS standards using a standard Vitalograph wedge-bellows spirometer.

\section{Statistical analysis}

For cross-sectional analysis between groups, an unpaired t-test was used to determine whether differences observed were significant. Correlations between RHML and other inflammatory markers in the asthmatic group were determined using a Pearson correlation coefficient. Data that were not normally distributed were log-normalised prior to correlation analysis. The repeatability of RHML was assessed by calculating the measurement error (intra-subject SD), using a method described by BLAND and ALTMAN [21]. Levels of significance were determined as $p<0.05$. Normally distributed data are expressed as mean \pm SD and non-normally distributed data are expressed as median (interquartile range).

\section{RESULTS}

Study groups were well matched (table 1). FEV1 (\% predicted) was significantly lower in stable asthma $(82.7 \pm 26.9 \%)$ compared with controls $(101.8 \pm 7.5 \%$; $<0.01)$. For RHML measurement, the enthalpy of the inspired air and the ventilatory

\begin{tabular}{|c|c|c|}
\hline \multirow[t]{2}{*}{ TABLE 1} & \multirow[b]{2}{*}{ Healthy control } & ory heat \\
\hline & & Stable asthma \\
\hline Age yrs & $41.6 \pm 13.1$ & $44.7 \pm 14.6$ \\
\hline Subjects $n$ & 18 & 23 \\
\hline Sex $F / M$ & $10 / 8$ & $17 / 6$ \\
\hline Height m & $1.68 \pm 0.07$ & $1.65 \pm 0.08$ \\
\hline FEV 1 \% pred & $101.8 \pm 7.5$ & $82.7 \pm 26.9 * \star$ \\
\hline Enthalpy of inspirate $\mathrm{J} \cdot \mathrm{g}^{-1}$ & $20.3 \pm 1.6$ & $21.9 \pm 1.6$ \\
\hline Minute ventilation $L \cdot \min ^{-1}$ & $16.1 \pm 2.3$ & $15.9 \pm 3.4$ \\
\hline RHML J.L $\mathbf{L}^{-1}$ & $91.9 \pm 4.5$ & $98.1 \pm 7.3^{\star \star}$ \\
\hline \multicolumn{3}{|c|}{$\begin{array}{l}\text { Data are presented as mean } \pm \mathrm{SD} \text { or } \mathrm{n} . \mathrm{F} \text { : female; } \mathrm{M} \text { : male: } \mathrm{FEV} 1 \text { : forced } \\
\text { expiratory volume in one second; } \% \text { pred: } \% \text { predicted; } \mathrm{RHML} \text { : respiratory } \\
\text { health and moisture loss. }{ }^{* *}: \mathrm{p}<0.01 \text {. }\end{array}$} \\
\hline
\end{tabular}
pattern were closely matched between groups. 
RHML was significantly elevated in patients with stable asthma $\left(98.1 \pm 7.3 \mathrm{~J} \cdot \mathrm{L}^{-1}\right)$ compared with control subjects $\left(91.9 \pm 4.5 \mathrm{~J} \cdot \mathrm{L}^{-1} ; \mathrm{p}<0.01\right.$; fig. 2). Repeat measurements in nine control subjects demonstrated a measurement error of $\pm 1.6 \mathrm{~J} \cdot \mathrm{L}^{-1}$, giving a $95 \% \mathrm{CI}$ of $\pm 3.1 \mathrm{~J} \cdot \mathrm{L}^{-1}$. Repeat measurements in eight stable asthmatics showed a measurement error for this test of $2.3 \mathrm{~J} \cdot \mathrm{L}^{-1}$, giving a $95 \% \mathrm{CI}$ of $\pm 4.6 \mathrm{~J} \cdot \mathrm{L}^{-1}$. In the asthmatic group, induced sputum collection was successful in 17 out of 23 patients. Sputum eosinophils were 6.8\% (4.9$18.6 \%), \quad F e, \mathrm{NO}_{250} 18.0 \mathrm{ppb}(11.4-31.9 \mathrm{ppb})$ and $\mathrm{EBC} \mathrm{pH}$ was $6.4 \pm 0.3$.

Subgroup analysis of the asthma group revealed that there was no significant difference in RHML between mild/moderate persistent asthma and severe asthma (97.8 versus $98.3 \mathrm{~J} \cdot \mathrm{L}^{-1}$; $\mathrm{p}=0.88$ ). There was also no significant difference in RHML between the 16 subjects who were on a regular LABA and subjects who were not $\left(98.3\right.$ versus $\left.97.5 \mathrm{~J} \cdot \mathrm{L}^{-1} ; \mathrm{p}=0.81\right)$.

\section{Correlations between markers}

There was a close correlation between RHML and $\log _{10}$ (sputum eosinophil percentage) in stable asthma $(r=0.73$, $\mathrm{p}<0.0001$; fig. 3) but no correlation with eNO ( $r=0.23)$, EBC $\mathrm{pH}(\mathrm{r}=-0.09)$, FEV1 $(\mathrm{r}=-0.21)$ or FEV1 \% pred $(\mathrm{r}=-0.04)$. There were no significant correlations between other markers.

\section{DISCUSSION}

An increase in RHML can be detected in patients with stable but persistent symptomatic asthma. In these patients, there is a strong correlation between RHML and sputum eosinophilia, a robust marker of asthmatic airway inflammation. This suggests that the elevation in RHML in asthma is due to increased airway inflammation.

Original measurements of the thermal behaviour of airways in lung disease first appeared in the Russian literature in the 1970s, with apparatus that integrated temperature changes against volume of exhaled air [7]. Improved apparatus was later used by the same group to demonstrate differences in caloric output between control subjects and several patient groups, including patients with bronchial asthma [8]. However, in the present study, cooler inspirate, targeted breathing to increase and standardise minute ventilation

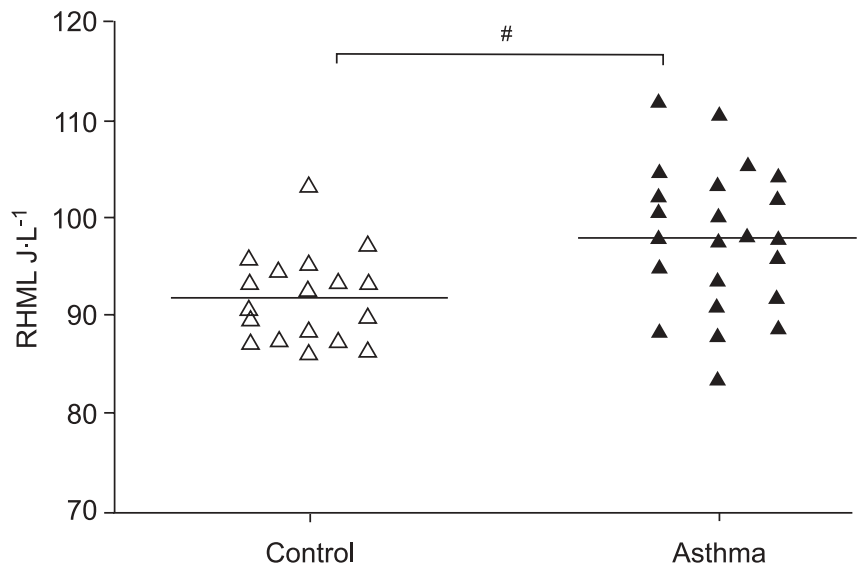

FIGURE 2. Respiratory heat and moisture loss (RHML) in healthy control subjects $(n=18)$ and patients with stable asthma $(n=23) .{ }^{*}: p=0.007$. (to engage the lower airway), and exhaled humidity measurement to quantify evaporative losses were used. These differences make a direct comparison of the present results with the previous study difficult.

As far as possible in a clinical setting, external factors that may influence respiratory heat loss were controlled. Inspiratory conditions were well controlled across groups and ventilatory pattern was well matched during each test. Minor differences in respiratory pattern were corrected for by expressing RHML per volume of expired air.

Drugs used in the treatment of asthma may have conflicting effects on airway mucosal blood flow, potentially confounding this measurement. Inhaled corticosteroids are vasoconstrictors, whereas $\beta_{2}$-agonists are vasodilators. Corticosteroids have been reported to reduce airway mucosal blood flow following 2 weeks' treatment [22]. This is likely to reflect a reduction in inflammation-related vascularity. The acute effect of inhaled corticosteroids on bronchial blood flow is reported to be a more transient vasoconstriction that is maximal at $30 \mathrm{~min}$ and has disappeared by $90 \mathrm{~min}$ [23]. In the context of the present study, the observed increase in RHML was seen despite potential confounding background vasoconstrictor effects of inhaled steroids. In contrast, salbutamol is reported to have a vasodilatory effect on the airway vasculature that may lead to an increase in respiratory heat loss [24]. Nebulised salbutamol can increase airway mucosal blood flow and breath-temperature gradients in control subjects, although this effect is not apparent in asthmatic patients who already have a higher baseline mucosal blood flow [23, 25]. There was no significant difference between patients taking a LABA and those not (98.3 versus $\left.97.5 \mathrm{~J} \cdot \mathrm{L}^{-1} ; \mathrm{p}=0.81\right)$. It is unlikely that LABA exerted an effect on RHML values. Patients withheld inhalers for $>12 \mathrm{~h}$ prior to testing, so it seems unlikely that the observed changes were due to asthma medication.

The possible effect of differences in work of breathing on RHML should be considered. However, there was no correlation between the severity of asthma, measured by FEV1\% pred, and RHML. Patients who have a higher work of breathing, therefore, do not appear to have higher RHML.

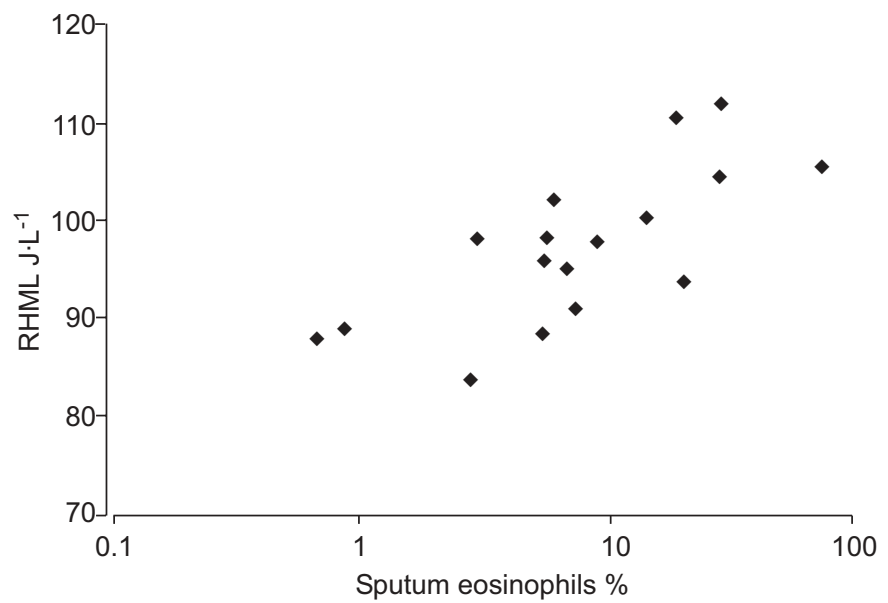

FIGURE 3. Correlation between respiratory heat and moisture loss (RHML) and sputum eosinophil percentage in stable asthma $(n=17 ; r=0.73 ; p<0.001)$ 
The link between RHML and sputum eosinophil percentage is an intriguing and novel correlation between a biophysical and a cellular marker. Monitoring sputum eosinophil percentage has been reported to have a positive impact on preventing asthma exacerbations when compared with conventional assessment of asthma in a randomised controlled trial [26]. A similar impact has not been demonstrated with other noninvasive markers of airway inflammation so far.

RHML did not correlate with FEV1, FEV1\% pred, eNO, or EBC $\mathrm{pH}$ in stable asthma. Spirometry does not always correlate consistently with markers of airway inflammation [27, 28]. This is probably because inflammatory markers provide information on current airway inflammation, whereas spirometry cannot distinguish between background structural damage or remodelling and present inflammation. Furthermore, the absence of a relationship between FEV1 and RHML in the asthmatic group reduces the possibility of the increase in RHML being an airway calibre effect.

In mild untreated asthma, eNO has been reported to correlate well with sputum eosinophils [29]. However, all patients in the current stable asthma group were taking regular inhaled corticosteroids, and in steroid-treated patients the relationship between NO and sputum eosinophils is much less pronounced $[27,28]$. These two markers vary in their response to inhaled steroid treatment [30, 31]. EBC $\mathrm{pH}$ has previously been reported to correlate with sputum eosinophils in asthma by KOSTIKAS et al. [32]. Important differences in the present study are that EBC samples were not deaerated prior to testing and the subjects had more severe asthma.

The results of the present study demonstrate that respiratory heat and moisture loss is elevated in a hospital-based outpatient asthmatic population. Furthermore, a close correlation has been shown between sputum eosinophil percentage and respiratory heat and moisture loss. Further investigations may help to establish the effects of asthma medications on respiratory heat and moisture loss and its utility in the longitudinal assessment of patients with persistent asthma.

\section{ACKNOWLEDGEMENTS}

The authors wish to thank M. Imrie and M. Dewar for assistance in processing sputum samples, and the Wellcome Trust Clinical Research Facility at the Western General Hospital, Edinburgh, UK.

\section{REFERENCES}

$1 \mathrm{Li} \mathrm{X}$, Wilson JW. Increased vascularity of the bronchial mucosa in mild asthma. Am J Respir Crit Care Med 1997; 156: 229-233.

2 Orsida BE, Li X, Hickey B, Thien F, Wilson JW, Walters EH. Vascularity in asthmatic airways: relation to inhaled steroid dose. Thorax 1999; 54: 289-295.

3 Salvato G. Quantitative and morphological analysis of the vascular bed in bronchial biopsy specimens from asthmatic and non-asthmatic subjects. Thorax 2001; 56: 902-906.

4 Tanaka H, Yamada G, Saikai T, et al. Increased airway vascularity in newly diagnosed asthma using a highmagnification bronchovideoscope. Am J Respir Crit Care Med 2003; 168: 1495-1499.
5 Kumar SD, Emery MJ, Atkins ND, Danta I, Wanner A. Airway mucosal blood flow in bronchial asthma. Am J Respir Crit Care Med 1998; 158: 153-156.

6 Walker JE, Wells RE Jr, Merrill EW. Heat and water exchange in the respiratory tract. Am J Med 1961; 30: 259-267.

7 Agarkov FT, Agarkov SF. [Calorimetric method of evaluation of the functional state of the apparatus of external respiration and its diagnostic efficacy]. Fiziol Zh SSSR Im I M Sechenova 1975; 61: 168-171.

8 Agarkov SF, Agarkov FT. [A method of recording respiratory heat loss.]. Fiziol Cheloveka 1990; 16: 169-172.

9 Paredi P, Kharitonov SA, Barnes PJ. Faster rise of exhaled breath temperature in asthma: a novel marker of airway inflammation? Am J Respir Crit Care Med 2002; 165: 181-184.

10 Ferrus L, Guenard H, Vardon G, Varene P. Respiratory water loss. Respir Physiol 1980; 39: 367-381.

11 Thomachot L, Viviand X, Lagier P, Dejode JM, Albanese J, Martin C. Measurement of tracheal temperature is not a reliable index of total respiratory heat loss in mechanically ventilated patients. Crit Care 2001; 5: 24-30.

12 McFadden ER Jr, Pichurko BM, Bowman HF, et al. Thermal mapping of the airways in humans. J Appl Physiol 1985; 58: 564-570.

13 McFadden ER Jr, Gilbert IA. Exercise-induced asthma. N Engl J Med 1994; 330: 1362-1367.

14 McCafferty JB, Kew PK, Haston A, Innes JA. A novel device for the precise measurement of respiratory heat and moisture loss. Thorax 2002; 57: Suppl. III, 56.

15 Masoli M, Fabian D, Holt S, Beasley R. The global burden of asthma: executive summary of the GINA Dissemination Committee report. Allergy 2004; 59: 469-478.

16 Respiratory heat and moisture loss in health, asthma and chronic obstructive pulmonary disease (COPD). MD thesis. University of Edinburgh, Edinburgh, UK, 2006.

17 Noble DD, Innes JA. Respiratory heat and moisture loss in stable asthma and acute exacerbations. Eur Respir J 2005; 26: Suppl. 49, 372s.

18 American Thoracic Society, European Respiratory Society, ATS/ERS recommendations for standardized procedures for the online and offline measurement of exhaled lower respiratory nitric oxide and nasal nitric oxide, 2005. Am J Respir Crit Care Med 2005; 171: 912-930.

19 Tate S, MacGregor G, Davis M, Innes JA, Greening AP. Airways in cystic fibrosis are acidified: detection by exhaled breath condensate. Thorax 2002; 57: 926-929.

20 Pavord ID, Pizzichini MM, Pizzichini E, Hargreave FE. The use of induced sputum to investigate airway inflammation. Thorax 1997; 52: 498-501.

21 Bland JM, Altman DG. Measurement error. BMJ 1996; 313: 744.

22 Brieva JL, Danta I, Wanner A. Effect of an inhaled glucocorticosteroid on airway mucosal blood flow in mild asthma. Am J Respir Crit Care Med 2000; 161: 293-296.

23 Kumar SD, Brieva JL, Danta I, Wanner A. Transient effect of inhaled fluticasone on airway mucosal blood flow in subjects with and without asthma. Am J Respir Crit Care Med 2000; 161: 918-921. 
24 Laitinen LA, Laitinen A, Widdicombe J. Effects of inflammatory and other mediators on airway vascular beds. Am Rev Respir Dis 1987; 135: S67-S70.

25 Paredi P, Kharitonov SA, Barnes PJ. Correlation of exhaled breath temperature with bronchial blood flow in asthma. Respir Res 2005; 6: 15.

26 Green RH, Brightling CE, McKenna S, et al. Asthma exacerbations and sputum eosinophil counts: a randomised controlled trial. Lancet 2002; 360: 1715-1721.

27 Leuppi JD, Salome CM, Jenkins CR, et al. Markers of airway inflammation and airway hyperresponsiveness in patients with well-controlled asthma. Eur Respir J 2001; 18: 444-450.

28 Stirling RG, Kharitonov SA, Campbell D, et al. Increase in exhaled nitric oxide levels in patients with difficult asthma and correlation with symptoms and disease severity despite treatment with oral and inhaled corticosteroids. Asthma and Allergy Group. Thorax 1998; 53: 1030-1034.
29 Jatakanon A, Lim S, Kharitonov SA, Chung KF, Barnes PJ. Correlation between exhaled nitric oxide, sputum eosinophils, and methacholine responsiveness in patients with mild asthma. Thorax 1998; 53: 91-95.

30 Jatakanon A, Kharitonov S, Lim S, Barnes PJ. Effect of differing doses of inhaled budesonide on markers of airway inflammation in patients with mild asthma. Thorax 1999; 54: 108-114.

31 van Rensen EL, Straathof KC, Veselic-Charvat MA, Zwinderman AH, Bel EH, Sterk PJ. Effect of inhaled steroids on airway hyperresponsiveness, sputum eosinophils, and exhaled nitric oxide levels in patients with asthma. Thorax 1999; 54: 403-408.

32 Kostikas K, Papatheodorou G, Ganas K, Psathakis K, Panagou P, Loukides S. pH in expired breath condensate of patients with inflammatory airway diseases. Am J Respir Crit Care Med 2002; 165: 1364-1370. 